\title{
GEHLEN Y LA SUTURA DEL DUALISMO SCHELERIANO ENTRE ESPÍRITU Y FUNCIONES
}

VITALES: La especificidad del organismo humano.

\author{
Juan J. Padial \\ Universidad de Málaga
}

\begin{abstract}
Resumen: Se expone en este trabajo el modo en que Arnold Gehlen sutura el dualismo entre espíritu y vida de Max Scheler. Gehlen, al investigar la diferencia en el plano meramente biológico de la motricidad, percepción e impulsividad humanas, del hombre con el resto de los animales, logra un sentido de la acción, que se vincula a la experiencia sobre el mundo y no al logos autoconsciente.

Palabras clave: Dualismo, Bioantropología, Arnold Gehlen, Animales, Acción.

Gehlen and the Suture of Schelerian Dualism Between Spirit and Vital Functions: the Specificity of the Human Organism.
\end{abstract}

Abstract: This paper discusses the way in which Arnold Gehlen sutures the dualism between spirit and life of Max Scheler. Gehlen, in investigating the difference at a merely biological plane of human motility, perception and impulsivity, of human being with the rest of animals, achieves a sense of action, which is linked to the experience of the world and not to the self-consciousness.

Key Words: Dualism, Bio-anthropology, Arnold Gehlen, Animals, Human being, Action.

Recibido: 16/10/2017 Aprobado: 5/11/2017 
Juan J. Padial

\section{Gehlen y la bioantropología}

Arnold Gehlen pertenece a la segunda generación de la antropología filosófica. Podemos caracterizar la primera generación, la de Scheler, Plessner y Cassirer, como la generación fundacional. Scheler y Plessner se consideran usualmente los fundadores de la bioantropología filosófica. El plano metodológico en el que se sitúan favorece una lectura no naturalista de los datos proporcionados por la biología, a cuyos hallazgos coetáneos atienden. Se trata de un plano metodológico que, a juicio de Gehlen, supuso

...un cambio notable y sorprendente, pues no interpretaba al hombre en comparación o relación con Dios, sino en la diferencia esencial entre hombre y animal. [...] Scheler inquiría acerca de la diferencia esencial entre dos maneras de ser y, al hacerlo, volvía inmediatamente a la indagación del problema biológico del hombre, ese mismo problema que se acostumbraba dejar a los zoólogos o a los médicos en calidad de “Antropología física”. (Gehlen, 1993: 31)

Así, en un primer acercamiento, estos autores proceden a indagar lo específico del vivir y la conducta biológica, en la que lo psíquico y lo anímico se entienden como fenómenos vitales, es decir propiamente biológicos. Respecto de este trasfondo, compartido con los animales, de fenómenos vitales se delinea lo específicamente humano. A juicio de Gehlen, aquí yace una nueva forma de dualismo, a cuya sutura responde su filosofar y el de la segunda generación de la Antropología filosófica. 
Gehlen intentó superar el dualismo entre la naturaleza biológica del ser humano y su logos autoconsciente insistiendo en la inviabilidad biológica del ser humano por la que este necesita de la cultura, es decir, del orbe de productos que suscita mediante su acción, y con los que remedia el carácter deficitario de su naturaleza. La acción humana compensa pues la inviabilidad de su organismo, y permite superar dualismos como los de Scheler, en los que el ser humano se define por su negación y distinción respecto de la vida. Esta idea de «compensación» será la clave antropológica para autores como Odo Marquard, Konrad Lorenz y Karl-Otto Apel, que aplicaron a otros temas esta idea gehleniana de la compensación.

La segunda generación, la de Gehlen, sigue insistiendo en la perspectiva bioantropológica, y por ello Antonio Aguilera ha subrayado que la filosofía de Gehlen, en una línea abierta por la filosofía clásica alemana y el romanticismo «se ocupa del matrimonio entre naturaleza y espíritu (Novalis)» (Aguilera, 1993: 10), entre lo biológico y lo cultural, entre lo orgánico y lo institucional.

Pero lo biológico y natural en el ser humano tiene la peculiaridad de lo monstruoso, de lo teratológico. El ser humano, todo ser humano, desde un punto de vista zoológico y etológico, es un ser anormal. Se aparta del patrón evolutivo común de especialización y adaptación al ambiente. Es por ello que la acción y la institución hunden sus raíces «en una monstruosa naturaleza carente de instintos, en la desmesura de un excedente impulsivo (Antriebsüberschuß) incapaz de ser satisfecho y que le arroja una vez y otra vez a 
Juan J. Padial

situaciones arriesgadas donde se procura medios para vivir». (Aguilera, 1993:

11)

\section{El teorema bioantropológico del ser carencial y deficitario}

Los esfuerzos de Gehlen se concentrarán en comprender el sentido de la peculiar constitución corporal humana dando lugar a la más conocida de sus obras: El ser humano. Su naturaleza y su posición en el mundo, aparecida en 1940. Se trata de una investigación no por el puesto del hombre en el cosmos, sino por su singular posición biológica. En esto seguía a algunos célebres biológos como el holandés Frederic Buytendijk, el austriaco Otto Storch, o el suizo Adolf Portmann.

La posición de Gehlen es — como la de Scheler y Plessner- también antireduccionista, o si se quiere, implica un enfrentamiento al naturalismo desde la consideración de la peculiar constitución biológica del ser humano. Pero a diferencia de Scheler, el antinaturalismo de Gehlen no lo lleva a un espiritualismo sino en la línea de Buytendijk a un establecimiento desde dentro de la misma biología de los límites que separan lo humano de lo animal no humano. Así tenemos a un discípulo de Driesch que no es vitalista, un colaborador en el campo de la antropología filosófica fundada por Scheler que no es fenomenólogo, y un antropobiólogo que no es naturalista. Pero pasemos de estas coordenadas definidas negativamente, a unas coordenadas positivas. 
Nuestra posición está en contraposición con todas aquellas que operan con una 'reducción' del ámbito anímico espiritual al ámbito orgánico. Por el contrario, constantemente se pone de manifiesto que aquello que suele adjudicarse y reservarse a los rendimientos espirituales, ya está 'anticipado' y 'tenido en cuenta' en los estratos vitales. Las funciones vegetativas, sensitivas y motoras trabajan manifiestamente de modo mucho más espiritual de lo que el idealismo quería y el materialismo podía conceder. Precisamente por ello, no es posible representarse estas funciones superiores en un organismo de cualquier otra forma estructurado, y no pueden ser, en última instancia, entendidas si no se lo considera en relación con la peculiaridad orgánica del hombre. (Gehlen, 1978: 20).

Gehlen rechaza tanto una consideración crasamente naturalista del ser humano como una tesis netamente espiritualista. Ni la diferencia para con el animal es tan sólo de grado, ni el espíritu ha de ser traído prematuramente al debate, como si el ser humano tan sólo se diferenciase del animal por razón de su espíritu. Un espíritu, que siguiendo la línea que va de Descartes a Scheler, fuese precisamente la negación de lo natural, lo opuesto a la naturaleza.

Es fundamentalmente falso indicar que la diferencia esencial entre el ser humano y el animal radica en primer lugar en la 'inteligencia'; la diferencia es ya anatómica, sensomotora. (Gehlen, 1978: 179)

Centrarse en la constitución biológica del ser humano implica renunciar a un esquema de niveles, como el que habían expuesto antes Scheler o Plessner. No es meramente la capacidad espiritual de poder-decir-no la que define al ser humano, sino también, y como señala el texto que hemos citado, sus 
Juan J. Padial

mismas funciones vegetativas, sensitivas y motoras. Ellas no se definen por contraposición a lo espiritual, como lo meramente corporal o material. Lo definitorio del ser humano no se encuentra en oposición a la naturaleza, sino en conexión con la naturaleza, con la constitución biológica del ser humano. Por ello, el objetivo de Gehlen en modo alguno equivale a comprender al hombre desde el animal, sino desde sí mismo: en la tarea que su morfología biológica le encomienda. Se trata de elaborar una antropología desde las condiciones de la existencia humana, desde su situación, ya biológica, ya mundanal.

En la constitución morfológica humana, si se la compara con la del resto de los antropoides, se observan primitivismos. Es como si el desarrollo de ciertos órganos hubiese quedado anclado o fijado en niveles muy tempranos del desarrollo fetal: la falta casi generalizada de pelo corporal, la forma de la pelvis, el elevado peso del cerebro, etc. Tal era la tesis del especialista holandés en anatomía Louis Bolk. El primitivismo, la inmadurez, es un retardo del desarrollo orgánico que se manifiesta también en la falta de agudeza perceptiva, la dificultad para estabilizar los movimientos, etc.

En línea con el mito de Prometeo y Epimeteo, narrado en el Protágoras de Platón, Gehlen describe al ser humano como un animal deficitario, un ser carencial -Mängelwesen, había señalado Herder- Esto es lo distintivo biológicamente de la especie humana: su indigencia. Tan importante es esta descripción para la Antropología Filosófica de Gehlen, que Rolf Darge y 
Martina Schmidhuber hablan del «teorema del ser deficitario como el principio heurístico de la antropología elemental» ${ }^{1}$ :

El ser humano, morfológicamente, está determinado —en contraposición al resto de los mamíferos superiores, principalmente por el déficit, lo que permite describirlo respectivamente, y en un sentido exactamente biológico como inadaptado, inespecializado y primitivo, o sea como no desarrollado. Es decir, como un organismo esencialmente negativo. Carece de pelaje corporal natural y con ello de la protección frente a la climatología. Le faltan órganos naturales de ataque, pero también de una formación corporal apropiada para la huida. El ser humano es sobrepasado por la mayor parte de los animales en agudeza sensorial. Tiene precisamente una carencia peligrosa para la vida de verdaderos instintos y está sujeto durante toda la lactancia y la niñez a una completa e incomparablemente larga necesidad de protección. Con otras palabras: en la esfera de condiciones naturales, originales, se habría exterminado hace ya mucho como viviente en medio de los ágiles animales que huyen y de los peligrosos depredadores. (Gehlen, 1978: 33)

Esta inespecialización, inadaptación, primitivismo y subdesarrollo de los órganos se puede apreciar con facilidad en la mano. Ni sus funciones, ni su forma, ni sus movimientos están terminados una vez acabado el periodo de gestación. Al contrario, al nacer, el ser humano es incapaz de casi cualquier

1 Cf: Darge-Schmidhuber, 2009. pp. 44-48. La biotecnología viene a ser una constatación en el ámbito de las ciencias empíricas de las tesis de Gehlen sobre el ser humano como un ser deficitario. Cfr.: Schoene, 1994: 491-542. También Engels, 2009: 207-236. 
movimiento. $\mathrm{Y}$ aquí, como mostró Otto Storch hay una diferencia neta para con la motricidad animal. A diferencia de la motricidad animal, la humana se caracteriza por su plasticidad. Mientras que la motricidad animal está filogenéticamente fijada y limitada a unas pocas posibilidades, la motricidad animal está abierta a un rango ilimitado de movimientos posibles y variados. La motricidad humana, y por lo tanto la existencia del ser humano, dependen pues ante todo del aprendizaje que ha de realizar cada hombre singular. Se trata de una motricidad que podríamos caracterizar como abierta a un ámbito ilimitado de variaciones y posibilidades, que surgen y se consolidan merced a la acción humana. Por ello Gehlen caracteriza al ser humano como ser carente: carece de especialización, carente de fijación, carece de adaptación, carece de desarrollo.

También se aprecia este primitivismo e inespecialización en la percepción que requiere también de aprendizaje y cooperación entre los diversos sentidos. De entrada, el ser humano no puede fiarse de sus sentidos, ha de educarlos, debe ponerlos-en-forma. Y esto no sólo ha de hacerlo para aprender a tocar un instrumento musical, por ejemplo. También y, sobre todo, para atender a sus necesidades biológicas, puesto que para sobrevivir ha de actuar, y ello implica usar cosas. Por otra parte, los estímulos que pueden tener sentido para la especie humana son en rigor infinitos. Por eso, la percepción humana también está sobrecargada. 
Geblen y la sutura del dualismo scheleriano

\section{Bioantropología y acción: el teorema del ser activo}

Así pues, la atención antropológica de Gehlen recae en un primer momento en la peculiar biología humana. Esta tematización conduce a una concepción de la acción como «la actividad destinada a modificar la naturaleza con fines útiles al hombre»(Gehlen, 1993: 32). Es decir, la acción se entiende desde lo natural, biológico y orgánico. Es acción en y con la naturaleza. De aquí el segundo momento de la bioantropología gehleniana: investigar la inserción de la acción y la racionalidad en la condición biológica del ser humano. En este sentido, Gehlen se inserta en la tradición kantiana de articulación entre lo racional y lo natural. Tradición que prosigue en nuestros días Robert Spaemann.

Éste es el enfoque de Gehlen ya desde su tesis doctoral. Arnold Gehlen se doctoró en Leipzig con Hans Driesch, realizando una tesis sobre el poner setzen-. En ella, Gehlen advierte que la relación del espíritu consigo mismo está siempre mediada por su actividad para con la naturaleza. La libertad se ejerce «en la afirmación sobre la naturaleza y merced a la adaptabilidad de la naturaleza a la libertad» (Gehlen 1986: 164). Una naturaleza que el hombre ha adaptado, mediante su acción, a sí, para favorecer y posibilitar su vida. Se observa ya en su tesis doctoral el papel sobresaliente que van a tener la libertad y la acción en su correlación con la plasticidad de lo humano y la potencialidad de lo natural (Rehberg, 1983: 10).

En sus obras propiamente antropobiológicas, Gehlen expone su tesis de la compensación. El ser humano como ser activo compensa la ineptitud bio- 
Juan J. Padial

lógica del ser carencial. Se trata de una acción dirigida ante todo a las condiciones naturales, a la naturaleza como medio ambiente. Es en y con la naturaleza, pero en una naturaleza siempre transformada, modificada activamente por el hombre, como éste puede compensar las deficiencias y carencias de su organismo biológico. Así, solo mediante el uso y la transformación del ambiente natural, puede el ser humano ser viable biológicamente. La acción y su corrección inciden sobre el medio exterior, y es la percepción de las consecuencias, favorables o perjudiciales, de la acción sobre el medio, lo que permite la modificación biológicamente exitosa de la acción.

El hombre, expuesto como el animal a la naturaleza agreste, con su físico y su deficiencia instintiva congénitos, sería en todas las circunstancias inepto para la vida. Pero esas deficiencias están compensadas por su capacidad de transformar la naturaleza inculta y cualquier ambiente natural, como quiera que esté constituido, de manera que se torne útil para su vida. Su postura erecta, su mano, su capacidad única de aprender, la flexibilidad de sus movimientos, su inteligencia, su objetividad —que Scheler ya había señalado—, la "apertura" de sus sentidos poco potentes, pero no limitados solamente a lo importante para los instintos; todo eso que puede considerarse un sistema, una conexión, capacita al hombre para elaborar racionalmente las condiciones naturales existentes en cada caso en la selva virgen, en el pantano, en el desierto o donde sea- para conservarse en cualquier constelación natural a mano, sea en zonas árticas o en el ecuador (Gehlen, 1993: 33).

El ser humano sólo puede relacionarse indirectamente consigo mismo, y esto implica que la acción humana no versa directamente sobre el espíritu, 
sino sobre la naturaleza. Esta es la perspectiva de Gehlen para quien la acción no sólo pone al sujeto en el mundo, es decir exterioriza la subjetividad e interioridad humanas, sino que sobre todo «modifica inteligentemente las condiciones naturales» (Rehberg 1983: 129). El hombre ha de construir, producir, una segunda naturaleza, un mundo que comparte con otros seres humanos. Y es que la libertad se pone siempre como respuesta a situaciones y a sus propias necesidades. Así, la necesidad de adaptar libremente la naturaleza - de actuar sobre ella y transformarla, modificarla - implica la apertura del ser humano al mundo, y la necesidad de construir mundos en los que la indigencia biológica que caracteriza a la naturaleza humana es remediada. Gehlen llega a caracterizar esta necesidad como una condena. Con esto está estrechamente relacionado el sentido gehleniano de «segunda naturaleza». En opinión de este autor la cultura no es meramente análoga a la naturaleza. No es que el principio de la naturaleza sea el ser y el de la cultura la libertad. La segunda naturaleza lo es para la radical indigencia de la naturaleza biológica del ser humano. Es la esfera suscitada por la acción humana que remedia los problemas que al ser humano le plantea su peculiar morfología biológica.

La respuesta humana a esta situación biológica consiste en la acción. Mediante ella el ser humano hace frente a las condiciones deficitarias de su existencia orgánica. Esto es lo definitorio del ser humano, su comportamiento, su acción. Acción - Handlung - se dice en alemán precisamente en referencia a uno de los órganos corporales, la mano - Hand- Y Ya la teoría de Bolk sobre la fetalización de los órganos humanos había podido dar una 
explicación suficiente de las proporciones y medidas de la mano. Así, en el lenguaje ordinario queda recogida la sugerencia de que es preciso entender la acción desde la peculiar morfología y biología humanas.

Además, al tener que actuar, al estar situado ante tareas enormes y onerosas que le reclaman para resolver sus necesidades y dominar sus intereses, el hombre ha de interpretar e interpretarse necesariamente. La tarea y la acción pertenecen tan constitutivamente al ser humano, que Gehlen llega a decir no sólo que el ser humano realiza o ejecuta tareas, sino que su propia physis, su misma naturaleza es ya una tarea para él. Es constitutiva y biológicamente actuante. Además, de la interpretación que hace de sí, dependen la interpretación que hace de sus tareas concretas en el mundo (Levy, 1994: 405-438.):

El hombre es el animal aún no fijado-constatado, no está 'colocado'. Es un ser que se encuentra constitutivamente ante una tarea (como una tarea) y que precisamente por ello necesita una interpretación de sí mismo. (Gehlen, 1978: 16).

Así desde un nivel puramente biológico dos son las características definitorias y propias de la esencia humana según Gehlen: es un ser carente (Mängelwesen) y un ser actuante (handelndes Wesen). Un ser que compensa su déficit biológico con su acción. Pero lo peculiar de Gehlen es la sutura del dualismo. Y eso implica que la acción humana no hunde sus raíces en el logos autoconsciente, sino en los mecanismos biológicos de regulación que Weizsaecker había descrito con su idea del ciclo estructural o activo Gestaltkreis-. Es decir, Gehlen evita el dualismo al hacer de la acción un proceso cíclico sumamente complejo, en el que la percepción de lo realizado 
sobre el medio permite la modificación del mismo actuar. La acción se conecta así con el resultado, con el éxito esperado que hace la vida posible y viable.

\section{Acción y plasticidad del organismo humano: la racionalidad del auerpo humano}

Veamos algunos de esos modos peculiarísimos de acción humana que lo diferencian del animal. La percepción visual es simbólica acerca del modo en que deben ser usadas y tratadas las cosas. Es decir, la percepción no está aislada de la motricidad, sino que forma un sistema o ciclo activo con ella. La percepción humana es inespecializada, del mismo modo que la motricidad no está fijada filogenéticamente. La percepción está abierta orgánicamente a toda la realidad - Weltoffen-, y no circunscrita a una serie de estímulos en un medio concreto. Pero merced a sus experiencias de éxito y de fracaso al manejar las cosas que percibe y sobre las que actúa, la percepción humana resulta «cargada». El hombre percibe visualmente sugerencias táctiles en las cosas que le hacen frente en su mundo: la solidez, fragilidad, peso, textura, dureza, etc. Cuando se ha logrado cargar lo visto con estas sugerencias táctiles y de uso, es el momento en que el mundo queda configurado como lo disponible.

El hombre es capaz de aprender las más complicadas combinaciones de movimientos en una diversidad verdaderamente infinita, cosa que nos muestran los artistas, los deportistas, los automovilistas y, en general, la práctica profesional. 
Juan J. Padial

Las decenas de miles de profesiones, trabajos y oficios en que se ocupa la humanidad requieren cada cual manipulaciones distintas y especiales, todas aprendidas, y esto es posible solamente porque no existe la estrecha precisión innata de los movimientos instintivos (Gehlen, 1993: 35).

Así, si la percepción, motricidad e instintividad animales se caracterizan por la precisión y adaptación de un número pequeño y restringido de impulsos, conductas y estímulos perceptibles, en el ser humano la vida biológica está caracterizada por una plasticidad y amplitud ilimitadas de lo perceptible y de movimientos adquiridos. Aprender a coordinar movimientos es especialmente importante dada la plasticidad motriz que caracteriza al organismo humano, y por la que se relaciona con las cosas del mundo y con otros seres humanos. Esta plasticidad - kinética - no es pues explicable como un retraso o una fetalización, al modo de Bolk, sino que «la característica fundamental del organismo humano desde el punto de vista morfológico y fisiológico es, precisamente, su plasticidad, y a eso es a lo que se puede llamar racionalidad del cuerpo humano» (Choza, 1989: 133). La variedad de movimientos -y de coordinación entre movimientos- humanos es inimaginable. También es infinita las variaciones que de los mismos pueden hacer los seres humanos.

Ya los filósofos antiguos habían realizado observaciones en esta dirección. De aquí el interés de Aristóteles por Las partes de los animales. Es en esta obra donde recoge el parecer de Anaxágoras sobre el conjunto más sobresaliente de efectores humanos: las manos. Anaxágoras había señalado que el ser humano es el viviente más inteligente porque tiene manos: ellas nos permiten 
manipular cualquier cosa. En este sentido parecen correlativas con la amplitud del intelecto. En esto consiste la rectificación de Aristóteles. Las manos son instrumentos de instrumentos, y el ser humano tiene manos porque es el más inteligente:

El hombre no es más inteligente gracias a las manos, sino que tiene manos porque es el más inteligente de los animales. En efecto, el ser más inteligente podría utilizar correctamente un gran número de órganos, y la mano no parece ser un solo órgano sino varios. Es como un órgano de órganos. Así pues, la naturaleza ha concedido el más útil de los órganos, la mano, al ser que es capaz de adquirir muchas habilidades. (Aristóteles, 2000: IV 10, 687a 8-10).

Aristóteles advierte la pluri-funcionalidad de este órgano, que rebasa una única finalidad. La mano no está especializada en ningún uso, y al nacer la precisión de sus movimientos es casi nula. Lo mismo sucede con el movimiento del resto de efectores, y del cuerpo en su conjunto. Ha de ser aprendido. La mano no tiene un fin biológicamente dado, sino que puede exceder sobre cualquier uso que naturalmente podría dársele porque carece de una finalidad específica. En este sentido depende del aprendizaje humano —de los hábitos que adquiera - y que dan nuevas finalidades a este órgano, haciéndolo como señala Aristóteles un instrumento de instrumentos. La pluri-funcionalidad es adquirida y tiene como base una plasticidad biológica inédita en un mundo animal caracterizado por la rigidez y la precisión motrices. 
Juan J. Padial

Pero la conexión mano-mundo es más estrecha, como Gehlen se encargaría de mostrar. Gehlen encuentra en las investigaciones de Adolf Portmann sobre la maduración extrauterina del organismo humano, la clave de la plasticidad motriz humana. Los seres humanos carecen de la madurez biológica debida al término del proceso de gestación, de modo que este se continúa extrauterinamente, es decir, en el medio cultural. Éste, y sólo éste permite la maduración biológica tras un periodo muy prolongado de vida fuera del seno materno. Sólo la interacción con el medio hace posible la maduración bio-psicológica humana. Así no hay recién nacido que no sea en rigor el fruto de un parto prematuro, y no hay maduración biopsicológica que no se deba a la acción e interacción con el medio.

En cuanto a percepción y movimiento, los procesos decisivos de maduración operan durante un año entero como situaciones de aprendizaje bajo la influencia orientadora del medio circundante. La capacidad de aprendizaje del ser humano y esta influencia orientadora de su medio están, por así decirlo, incluidas en el plan de desarrollo puramente biológico, siendo el niño típica y normalmente (aunque anormalmente en comparación con el animal) sacado del cuerpo materno para ser sometido a dicha influencia (Gehlen, 1993: 36).

Esta peculiar y prolongada maduración biológica extrauterina ponen en juego una cantidad enorme de ciclos activos, en los que la percepción del éxito de lo intentado sobre el medio configura la motricidad y con ella la percepción humana. Esta configuración es un troquelado de la misma, que queda así consolidada desde la primera infancia, como mostró Bolk. Es obvio 
que la acción no está guiada en estos primeros momentos de la vida humana desde la conciencia. No se trata de procesos conscientes, aunque si de procesos experienciales, en los que lo consolidado al cabo del proceso de maduración extrauterina permite un saber cómo. Permite un hábito o técnica corporal precisa y exitosa, que a su vez es un modo racional de enfrentarse a las exigencias que la realidad plantea y la supervivencia biológica exige.

$\mathrm{Y}$ es que las experiencias repetidas de manipulación, de seguir con la mano, agarrar, arrastrar, golpear, etc., incorporan el mundo a la interioridad humana, lo hacen un mundo del que tenemos certeza. Es decir, nos abren al mundo en las experiencias que tenemos de él. Estamos abiertos al mundo mediante la acción. No es casual que acción se diga en alemán Hand-lung. E1 mundo no es meramente lo abierto para la inteligencia. También es lo abierto al actuar y gracias a la acción sobre el medio. Las manos son así órgano, pero un órgano mediador entre las cosas que nos hacen frente y nuestro cuerpo. $\mathrm{Y}$ es por esta mediación que el mundo y la propia realidad son alteradas en y por la acción manual. El mundo resulta así lo asible, o inasible, lo trasladable, lo que ha de ser manejado de tal o cual modo. El propio cuerpo es transformado merced a los hábitos corporales, las primeras técnicas que el hombre desarrolla, tanto en sentido biográfico como histórico (Mauss: 1971).

En la apertura al mundo tiene un papel decisivo el juego:

$\mathrm{El}$ juego es la forma en que se abre al mundo un ser que, aunque es abierto al mundo, todavía carece de tareas - a causa de su largo desarrollo- y está sobrecargado de vida pulsional. Y mediante el juego experiencia en una vitalidad 
Juan J. Padial

comunicativa, cómo se despiertan en él mismo una plenitud de necesidades de participación y de intercambio (Gehlen, 1978: 214).

En estas necesidades comunicativas hunde sus raíces el lenguaje humano. Gehlen investiga estas raíces en la conexión percepción-movimiento, es decir, en la coordinación sensomotora, por la que sentimos sonidos y los reconocemos; vemos cosas a las que respondemos - o llamamos- con exclamaciones sonoras o expresamos sonoramente nuestras necesidades; por último, y en el grado más alto coordinamos vicariamente nuestras acciones mediante palabras o gestos sonoros. ${ }^{2}$

En definitiva, el lenguaje surge también de una tarea ante las cosas. Una tarea que no tiene como propósito primario la modificación de la cosa, sino el mencionarla y comunicar sobre ella. Es por ello que en el lenguaje culminaría la tarea transformadora del mundo. Aquí lo primario ya no es la transformación sino el saber de la cosa, y de la disposición del mundo que hemos logrado mediante nuestras acciones. Pero precisamente por ello, el lenguaje hace posible infinitos nuevos modos de transformación y habitación del mundo humano.

2 Jacinto Choza ha desarrollado estas sugerencias de Gehlen intentando comprender los orígenes del lenguaje desde las acciones rituales. Cfr.: Choza, J. Filosofía de la cultura, Thémata, Sevilla, 2014. 


\section{Bibliografia empleada}

Aguilera, A., «Introducción» en Gehlen, A., Antropología filosófica. Del encuentro y descubrimiento del hombre por si mismo, Paidós, Barcelona, 1993.

Aristóteles, Las partes de los animales, Gredos, Madrid, 2000.

Choza, J. Filosofía de la cultura, Thémata, Sevilla, 2014.

Choza, J., Manual de Antropología Filosófica, Rialp, Madrid, 1989

Darge, R., Schmidhuber, M., «Das Mängelwesentheorem bei Arnold Gehlen» en Schmidinger, H., Sedmak, Cl., (eds.) Der Mensch- ein Mängelwesen? Endlichkeit Kompensation -Entwicklung, Wissenschaftliche Buchgesellschaft, Darmstadt, 2009.

Engels, E.-M., «Der Mensch, ein Mängelwesen? Biotechniken im Kontext anthropologischer und ethischer Überlegungen» en Schmidinger, H., Sedmak, Cl., (eds.) Der Mensch- ein Mängelwesen? Endlichkeit - Kompensation - Entwicklung, Wissenschaftliche Buchgesellschaft, Darmstadt, 2009

Gehlen, A., Antropología filosófica. Del encuentro y descubrimiento del hombre por sí mismo, Paidós, Barcelona, 1993

Gehlen, A., Der Mensch. Seine Natur und seine Stellung in der Welt, 12 edición, Wiesbaden, 1978

Gehlen, A., Wirklicher und unwirklicher Geist. Eine philosophische Untersuchung in der Methode absoluter Phänomenologie, en Gesamtausgabe, vol. I: Philosphische Schriften 1 (19251933), Klostermann, Frankfurt am Main, 1986

Levy, D. J., «Gehlen's Anthropology and the Foundations of Hermeneutic Understanding» en Klages, H., Quaritsch, H., Zur geisteswissenschaftlichen Bedeutung Arnold Geblens, Duncker \& Humboldt, Berlin, 1994

Mauss, M., "Les Techniques du corps", en Journal de Psychologie 32 (3-4)/ 1934, recogido en Sociologie et anthropologie, 1936, París, PUF. Traducción al castellano: Sociología y antropología, Tecnos, 1971

Rehberg, K,-S., «L' «antropologia elementare» di Arnold Gehlen» en Gehlen, A., L'Uomo. La sua natura e il suo posto nel mondo, Feltrinelli, Milán, 1983 
Juan J. Padial

Schoene, W., «Medizintechnologie -ein 'Kontrastprogramm' zur Gehlenschen Anthropologie» en Klages, H., Quaritsch, H., Zur geisteswissenschaftlichen Bedeutung Arnold Gehlens, Duncker \& Humboldt, Berlin, 1994., pp. 491-542.

Juan J. Padial

jjpadial@uma.es

Naturaleza y Libertad. Número 10, 2018. ISSN: 2254-9668 